\title{
Integrating Hands-On Undergraduate Research in an Applied Spatial Science Senior Level Capstone Course
}

\author{
David L. Kulhavy ${ }^{1}$, Daniel R. Unger ${ }^{1}$, I-Kuai Hung ${ }^{1} \&$ David Douglass ${ }^{1}$ \\ ${ }^{1}$ Arthur Temple College of Forestry and Agriculture, Stephen F. Austin State University, Nacogdoches, Texas, USA \\ Correspondence: Daniel R. Unger, Arthur Temple College of Forestry and Agriculture, Stephen F. Austin State \\ University, Nacogdoches, Texas, U.S.A. Tel: 1-936-468-3301. E-mail: unger@sfasu.edu
}

Received: November 17, 2014

Accepted: December 7, 2014

Online Published: December 9, 2014

doi:10.5430/ijhe.v4n1p52

URL: http://dx.doi.org/10.5430/ijhe.v4n1p52

\begin{abstract}
A senior within a spatial science Ecological Planning capstone course designed an undergraduate research project to increase his spatial science expertise and to assess the hands-on instruction methodology employed within the Bachelor of Science in Spatial Science program at Stephen F Austin State University. The height of 30 building features estimated remotely with LiDAR data, within the Pictometry remotely sensed web-based interface, and in situ with a laser rangefinder were compared to actual building feature height measurements. A comparison of estimated height with actual height indicated that all three estimation techniques tested were unbiased estimators of height. An ANOVA, conducted on the absolute height errors resulting in a p-value of 0.035, concluded the three height estimating techniques were statistically different at the $95 \%$ confidence interval. A Tukey pair-wise test found the remotely sensed Pictometry web-based interface was statistically more accurate than LiDAR data, while the laser range finder was not different from the others. The results indicate that height estimates within the Pictometry web-based interface could be used in lieu of time consuming and costly in situ height measurements. The findings also validate the interactive hands-on instruction methodology employed by Geographic Information Systems faculty within the Arthur Temple College of Forestry and Agriculture in producing spatial science graduates capable of utilizing spatial science technology to accurately quantify, qualify, map, and monitor natural resources.
\end{abstract}

Keywords: Spatial science, Hands-on, Real-world applications, Capstone course, Forestry, Natural resources

\section{Introduction}

\subsection{Spatial Science within a Natural Resource Curriculum}

Undergraduate students completing a Bachelor of Science degree in Spatial Science in the Arthur Temple College of Forestry and Agriculture (ATCOFA) at Stephen F. Austin State University (SFA), Nacogdoches, Texas, USA, concentrate on learning real-world applications of spatial science technology within a natural resource context. The mission statement of ATCOFA is to maintain excellence in teaching, research and outreach to enhance the health and vitality of the environment through sustainable management, conservation, and protection of natural resources. The college is dedicated to comprehensive undergraduate and graduate education, basic and applied research programs, and service (Bullard, Coble, Coble, Darville, \& Stephens-Williams, 2014). To achieve the mission statement, undergraduate course work in the Spatial Science program within ATCOFA focuses not only on traditional classroom instruction combined with outdoor lab instruction but also focuses heavily on integrating hands-on instruction via one-on-one faculty interaction to produce a more well-rounded and more competent graduate. Students who attend ATCOFA for the Spatial Science degree focus on hands-on instruction, field exercises and real-world applications using the most current geospatial technology (Unger, Kulhavy, Hung, \& Zhang, 2014).

Spatial science is the study of spatial information describing the Earth, its physical features and the built environment. Spatial technology, which has been identified as one of the targeted industry sectors within the United States by the President's High Growth Job Training Initiative, incorporates aerial photo interpretation, digital image processing, geographic information systems (GIS), and global positioning systems (GPS) technology. In addition, spatial science was identified as one of the important tools in forestry and natural resources in a recent ATCOFA curriculum reevaluation (Bullard, Coble, Coble, Darville, \& Stephens-Williams, 2014)

Within ATCOFA, the focus is on training undergraduate students in the Spatial Science program how to use aerial photographs, remotely sensed digital imagery, GIS, and GPS to quantify, qualify, map, and monitor natural resources 
to solve problems, issues, and concerns natural resource managers address on a daily basis. Within the Spatial Science program students can opt for one of two emphasis tracks: Natural Resources or Surveying.

Undergraduate students pursuing the Bachelor of Science degree in Spatial Science must complete 120 credit hours of instruction. General education requirements at SFA equal 42 credits. A student must also complete a common core of spatial science related course work equaling 42 credits while the student chooses an additional 36 hours of spatial science or natural resource related course work depending on their chosen option within the program.

Throughout their undergraduate career within ATCOFA, and in particular within the spatial science core and major, the focus of the faculty is on instructing students within an intensive hands-on environment to maximize one-on-one faculty interaction. Spatial science relies on computer software and a focus on hands-on instruction is crucial to a student's success and mastery of both the theoretical and applied aspects of spatial science.

The focus of one-on-one faculty instruction culminates in a senior level capstone course entitled Ecological Planning that incorporates elements from each of their previous courses. Within Ecological Planning students are required to complete a real-world research project incorporating both laboratory and field data that portrays their mastery of spatial science technology.

Examples of research projects previously completed include designing a national historic trail that incorporates local history and culture into an interactive GIS system, using a remotely controlled drone to rate the health of urban forest trees from a distance, and mapping the spatial distribution of endangered plants using high spatial resolution remotely sensed data. Although technically assigned to one faculty member, all faculty members within the spatial science program contribute to the individual student research projects within the senior level capstone course by design to increase a student's mastery of applied spatial science.

\subsection{The Need for Accurate Height Measurements}

Knowing the height of features on the Earth's surface is crucial to any spatial science endeavor. Although the spatial location of geographic features is crucial to understanding their role within a natural resource or non-natural resource context, the vertical height of a surface feature like a bridge, building, tree, or an eagle's nest above ground is also crucial to its management. Although vertical height can be estimated in situ with a traditional laser rangefinder it can be time consuming and expensive to estimate and record the in situ height of multiple surface features within an inaccessible or large geographic area (Asner et al., 2002).

Remote sensing represents the ability to obtain information about the Earth's surface from a distance using electromagnetic energy. Remote sensing, which has been a mainstay of spatial science for decades, typically involves using aerial photographs or remotely sensed digital imagery to quantify and qualify natural resources (Campbell \& Wynne, 2011). Remote sensing with its ability to collect data from a synoptic perspective has the advantage of acquiring information over a wide geographic area within one image and can be more efficient in terms of cost and time than in situ assessments.

\subsubsection{LiDAR Data}

Light Detection and Ranging (LiDAR) data, a relatively new form of remotely sensed data as compared to traditional digital or analog imagery obtained from satellites or an aerial platform, are currently being integrated into the undergraduate spatial science curriculum within ATCOFA. LiDAR data have been used to measure the height of vertical features within a landscape by using laser-scanning from an airplane to estimate height and elevation of the physical features of the landscape (Gatziolis, Fried, \& Monleon, 2010; Jurisch \& Mountain, 2008; Maltamo, Hyyppa, $\&$ Malinen, 2006). The return time from a surface feature back to the LiDAR scanner for each pulse of light is used to estimate surface elevation of a geographic feature. The difference in elevation between the top of an object and the bare ground it stands on is the object's measured height.

Using narrow-beam LiDAR, height estimates were within $0.43 \mathrm{~m}$ of actual tree height; and $0.55 \mathrm{~m}$ of actual tree height using wide-beam LiDAR (Anderson, Reutebuch, \& McGaughey, 2006). Popescu and Wynne (2004) and Popescu, Wayne and Nelson (2002) found LiDAR and multispectral data fusion were satisfactory in estimating forest plot-level tree height accounting for 97\% of the variation. O'Beirne (2012) calculated coefficient of determinations ranging from 0.92 to 0.96 comparing LiDAR data to field height measurements of trees in an urban environment.

\subsubsection{Pictometry Data}

High spatial resolution multispectral Pictometry data, another relatively new form of remotely sensed data, are combined into a web-based interface that has the potential to revolutionize height estimation from a distance. Pictometry data are also being integrated into the undergraduate spatial science program within ATCOFA to 
introduce spatial science students to cutting edge technology. Pictometry is an aerial application process patented by Pictometry International Corporation (Rochester, NY) and is classified as hyperspatial resolution remotely sensed data. Pictometry is acquired by low-flying aircraft to obtain images representing a vertical perspective and oblique angles up to 40 degrees to create a composite image used to estimate surface object size within seconds using the Pictometry web-based interface (Dailey, 2008; Gerke \& Kerle, 2011; Wang, Schultz, \& Giuffrida, 2008).

Dailey (2008) compared 3-dimensional measurements derived from Pictometry data with in situ survey measurements and calculated a Root Mean Square Error (RMSE) of $0.82 \mathrm{~m}$ between actual and estimated building height using Pictometry data. Unger, Hung and Kulhavy (2014) and Unger, Kulhavy, Williams, Creech and Hung (2014) demonstrated the utility and accuracy of estimating height of light poles and baldcypress trees using Pictometry data and found Pictometry estimated light pole height to be within $2.39 \%$ absolute error of actual light pole height and a linear correlation of 0.99 between Pictometry estimated tree height and in situ tree height.

\subsection{Study Objectives}

A senior within the Ecological Planning capstone course, with the aid of the GIS faculty, designed an undergraduate research project to: (1) increase his spatial science expertise by learning how to estimate the height of surface features from a distance using remotely sensed data; and (2) to assess the hands-on instruction methodology employed within the Bachelor of Science in Spatial Science program within ATCOFA at SFA. The overall objective was to compare the accuracy of estimating the height of 30 building features within the U. S. Department of Agriculture, Forest Service, Stephen F. Austin Experimental Forest (SFAEF) remotely with LiDAR and Pictometry data versus in situ height estimates.

\section{Methods}

\subsection{Study Site}

The SFAEF was chosen as the study site due to its proximity and accessibility to SFA students and faculty, is the only geographic area within close proximity to SFA that has both LiDAR and Pictometry data coverage, and has buildings within the coverage area with physical dimensions that would not change between dates of remotely sensed data acquisition and in situ measurements (Figure 1).

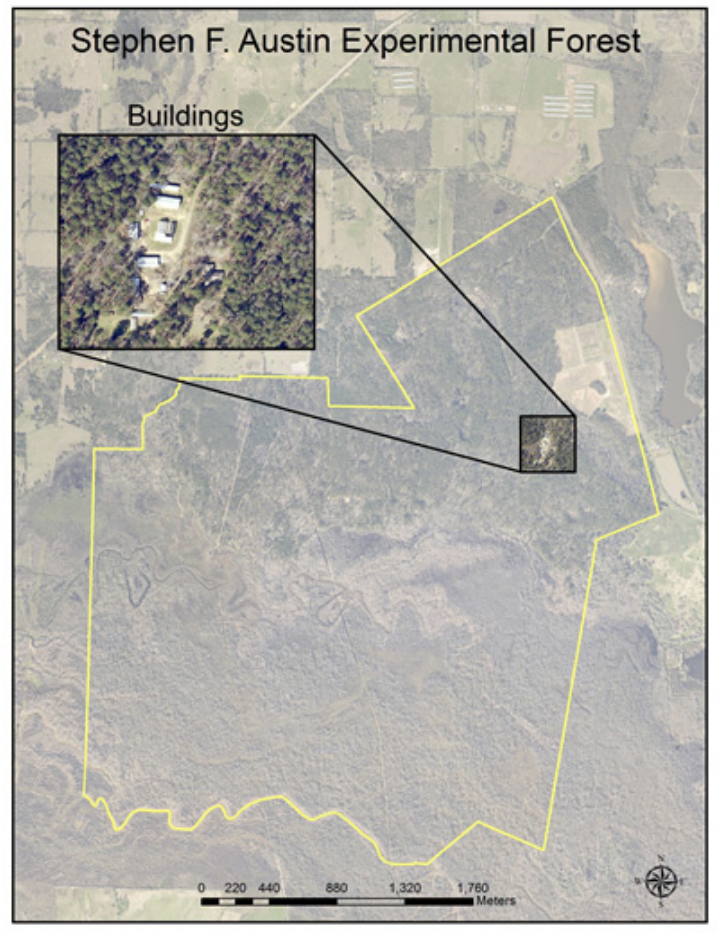

Figure 1. Study site depicting buildings within the U. S. Department of Agriculture, Forest Service, Stephen F. Austin Experimental Forest. 


\subsection{Hands-On Computer Measurements in the GIS Lab}

Undergraduate course work in the Spatial Science program within ATCOFA focuses on traditional classroom instruction and relies heavily on integrating hands-on instruction via one-on-one faculty interaction within a computerized environment to produce a more well-rounded and more competent spatial science graduate. The GIS faculty within ATCOFA is proud of the fact that they devote one-on-one time with each individual student to maximize their learning potential. Students within ATCOFA receive hands-on instruction daily using top-of-the-line GIS computer facilities with cutting edge spatial science software necessary to succeed in the spatial science workforce (Figure 2).

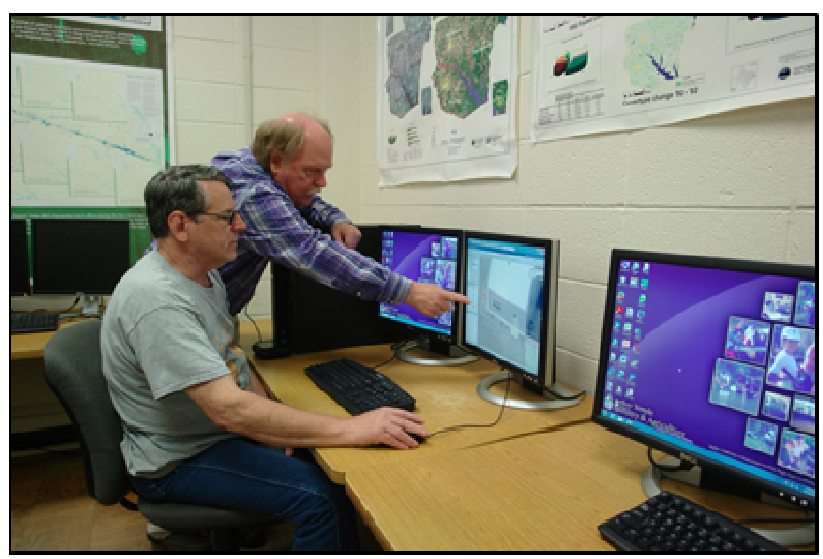

Figure 2. Student receiving hands-on faculty instruction within a GIS computer lab.

In 2013 ATCOFA partnered with a consortium of users including the County of Nacogdoches 911 District, the City of Nacogdoches, Texas, and the Nacogdoches County Appraisal District. The purchase included Pictometry imagery covering the City of Nacogdoches at $10.2 \mathrm{~cm}$ spatial resolution and the entire County of Nacogdoches at $23.0 \mathrm{~cm}$ spatial resolution; the typical spatial resolution acquired with Pictometry data representing local neighborhoods and community level coverage respectfully (EFS, 2007). After designing his research project the senior spatial science undergraduate student was instructed how to measure the height of building features remotely using the Pictometry web-based interface. Pictometry data with image acquisition date of the SFAEF of February 2013 was chosen since the physical dimensions of the building features measured would not change between Pictometry image acquisition date and the date of in situ height assessment. The senior spatial science student was first shown how to measure the height of building features within the Pictometry web-based interface before being allowed to record measurements himself. Pictometry on-screen view settings were either North, South, East, or West depending on the best oblique angle to observe building height. Once the student demonstrated to the GIS faculty his mastery of measuring object height using the patented Pictometry interface, the student was then allowed to estimate the height of 30 building features for comparison with LiDAR and in situ measurements (Figure 3).

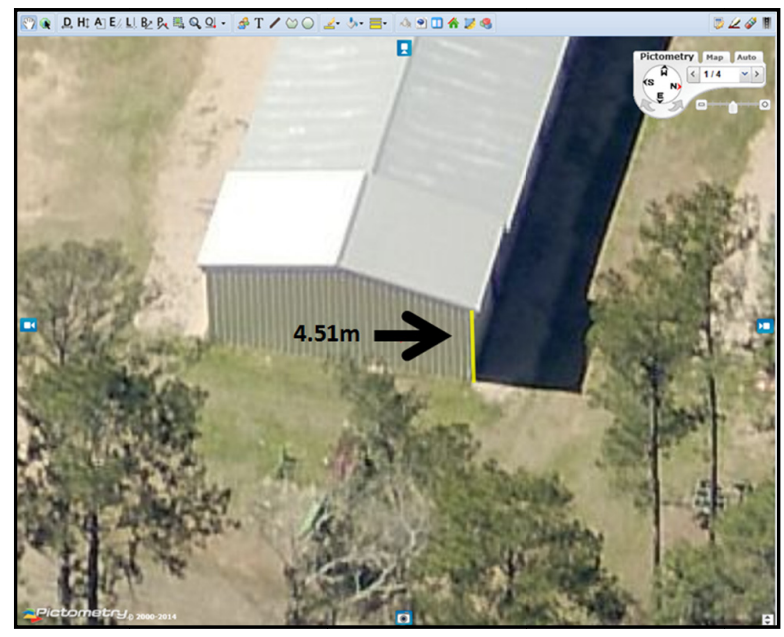

Figure 3. Example of estimating building feature height within the Pictometry web-based interface. 
LiDAR data covering the SFAEF was acquired in August 15, 2007 using a small-footprint LiDAR system that captured discrete, multiple return data with a density of 5.67 points per $\mathrm{m}^{2}$. The LiDAR was acquired using a Leica ASD50-II LiDAR system in cooperation with SFA and the Surdex Corporation (Chapman, Hung, \& Tippen, 2010). The senior spatial science undergraduate student was instructed how to measure the height of building features remotely using LiDAR data in conjunction with ArcMap 10.1 GIS software developed by Environmental Systems Research Institute (Redlands, California). LiDAR data of the SFAEF of August 2007 was chosen since the physical dimensions of the building features measured would not change between LiDAR data acquisition and in situ height assessment. The senior spatial science student was first shown how to measure the height of building features using LiDAR data within ArcMap 10.1 before being allowed to record measurements himself. Once the student demonstrated to the GIS faculty his mastery of measuring height features using LiDAR data, the student was then allowed to estimate the height of the same 30 building features for comparison with Pictometry and in situ measurements (Figure 4).

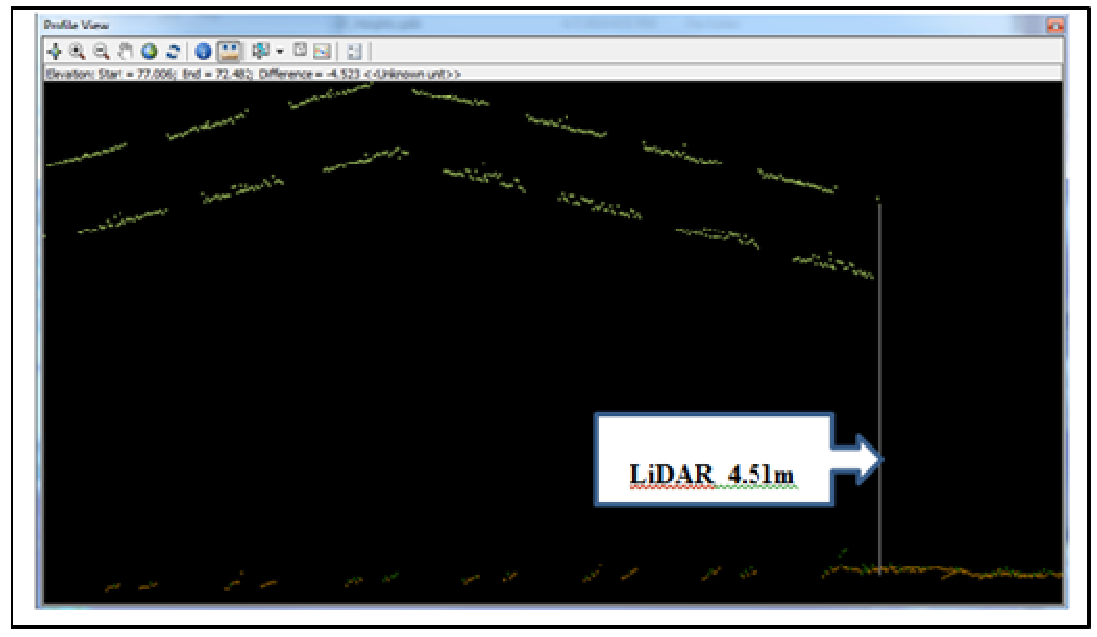

Figure 4. Example of estimating building feature height with LiDAR data within ArcMap 10.1 GIS software.

\subsection{Field Measurements}

Once the Pictometry and LiDAR height estimates in the GIS lab were recorded, the senior spatial science undergraduate student estimated the height of the 30 building features in situ using a TruPulse 200B rangefinder from Laser Technology, Inc. A laser rangefinder was included in the analysis of height since it has been traditionally used in the field and has a history of providing accurate height estimates (Figure 5).

After the Pictometry, LiDAR and laser rangefinder height estimates were recorded, the senior spatial science undergraduate student recorded the actual height of all 30 building features in situ with a telescopic height pole to the nearest $0.254 \mathrm{~cm}$. The actual height of each building feature was recorded last to eliminate preconceived notions of what the height of each building feature should have been when estimating height remotely via the Pictometry web-based interface, LiDAR data within ArcMap 10.1, or in situ with the laser rangefinder (Figure 6).

\subsection{Statistical Analysis}

In order to assess the accuracy of the remotely sensed height measurements and ATCOFA's hands-on instruction methodology, the 30 Pictometry, LiDAR, and laser rangefinder height estimates were compared to the actual building height features that were recorded in situ with a telescopic height pole. For each remote sensing method assessed, measurement errors were calculated for mean error, mean absolute error, mean absolute percent error, and RMSE. An analysis of variance (ANOVA) was conducted on the absolute height errors to determine if accuracy differences in height measurement among the three remote sensing methods tested were statistically significant. When found significant, a Tukey pair-wise test was applied to identify how the three remotely sensed height estimation techniques differed in accuracy. 


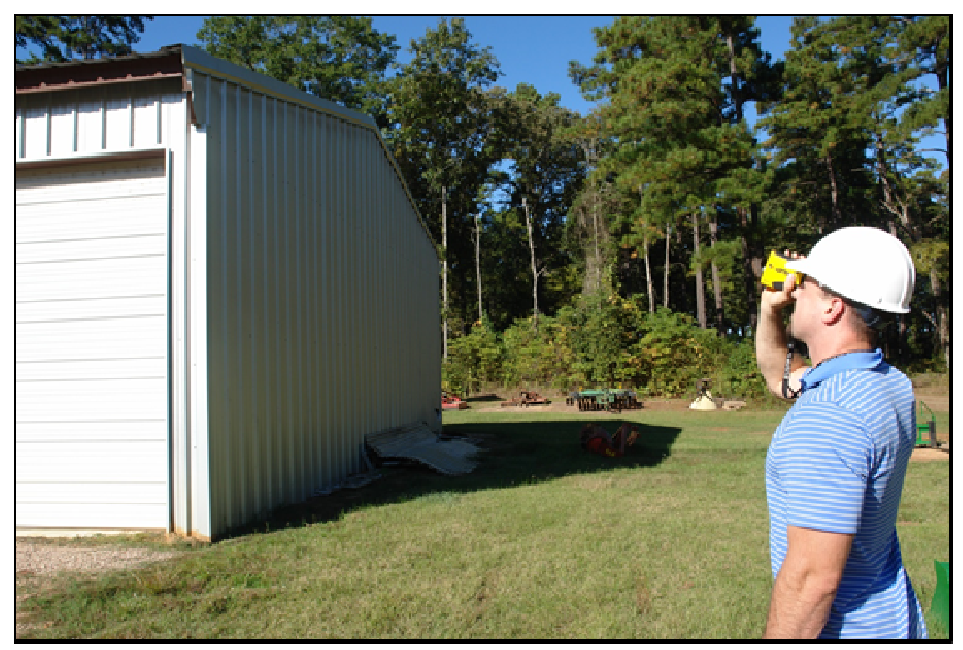

Figure 5. Estimating building feature in the field with a laser rangefinder.

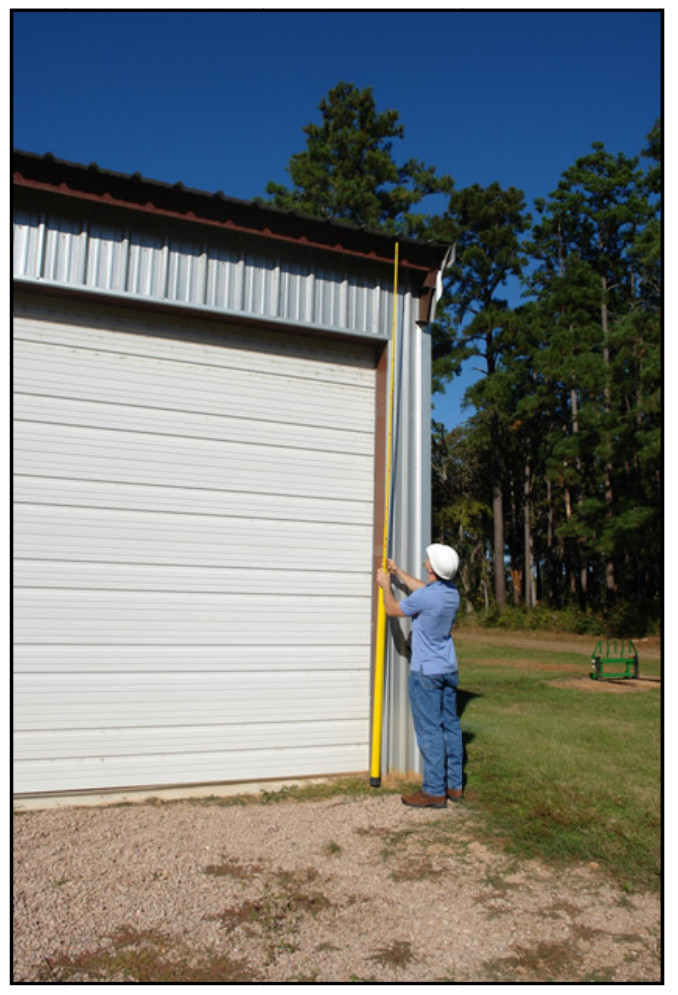

Figure 6. Measuring actual building feature height with a telescopic height pole.

\section{Results}

\subsection{Raw Data Analysis}

A summary of all 30 building feature in situ height measurements and all 30 remotely sensed building feature height estimates using Pictometry data, LiDAR data, and a laser rangefinder are displayed in Table 1. On average, LiDAR overestimated building features height, while both Pictometry and the laser range finder underestimated the 30 building features. However, all mean errors were very close to zero with $-0.07 \mathrm{~m}$ for the Pictometry web-based 
Table 1. Summary of all 30 building feature actual height measurements and in situ height estimates.

\begin{tabular}{rrrrr}
\hline Site & $\begin{array}{r}\text { Actual Height } \\
\text { (meters) }\end{array}$ & $\begin{array}{r}\text { Pictometry } \\
\text { (meters) }\end{array}$ & $\begin{array}{r}\text { LiDAR } \\
\text { (meters) }\end{array}$ & $\begin{array}{r}\text { Laser } \\
\text { (meters) }\end{array}$ \\
\hline 1 & 4.54 & 4.47 & 4.82 & 4.33 \\
2 & 6.01 & 5.95 & 6.23 & 5.61 \\
3 & 4.57 & 4.60 & 4.52 & 4.57 \\
4 & 3.76 & 3.66 & 3.87 & 3.60 \\
5 & 3.58 & 3.52 & 3.70 & 3.51 \\
6 & 4.51 & 4.47 & 4.64 & 4.45 \\
7 & 4.55 & 4.47 & 4.49 & 4.54 \\
8 & 5.23 & 5.13 & 5.54 & 5.18 \\
9 & 5.32 & 5.25 & 5.20 & 5.12 \\
10 & 3.58 & 3.19 & 3.31 & 3.51 \\
11 & 4.85 & 4.89 & 4.98 & 4.66 \\
12 & 3.61 & 3.63 & 3.69 & 3.57 \\
13 & 3.41 & 3.33 & 3.28 & 3.45 \\
14 & 3.45 & 3.36 & 3.56 & 3.41 \\
15 & 2.66 & 2.43 & 2.56 & 2.62 \\
16 & 2.49 & 2.44 & 2.54 & 2.41 \\
17 & 3.61 & 3.53 & 3.61 & 3.57 \\
18 & 2.33 & 2.26 & 2.60 & 2.23 \\
19 & 2.20 & 2.13 & 2.35 & 2.13 \\
20 & 2.27 & 2.27 & 2.54 & 2.16 \\
21 & 5.34 & 5.38 & 5.29 & 5.49 \\
22 & 2.13 & 2.13 & 2.27 & 2.01 \\
23 & 2.53 & 2.41 & 2.59 & 2.53 \\
24 & 3.67 & 3.48 & 3.91 & 3.81 \\
25 & 2.66 & 2.68 & 2.70 & 2.53 \\
26 & 3.45 & 3.47 & 3.32 & 3.38 \\
27 & 3.39 & 3.37 & 3.39 & 3.20 \\
28 & 4.60 & 4.63 & 4.54 & 4.42 \\
29 & 4.52 & 4.36 & 4.72 & 4.30 \\
30 & 3.57 & 3.51 & 3.84 & 3.57 \\
\hline Mean & 3.75 & 3.68 & 3.82 & 3.66
\end{tabular}

interface estimates, $0.07 \mathrm{~m}$ for the LiDAR data height estimates, and $-0.09 \mathrm{~m}$ for the laser rangefinder estimates indicating that all three estimation techniques tested were unbiased estimators of height. For an average accuracy comparison, the LiDAR data were found the least accurate among the three, with the highest mean absolute error $(0.14 \mathrm{~m})$, the highest mean absolute percent error $(4.00 \%)$, and the highest RMSE $(0.16 \mathrm{~m})$ (Table 2).

\subsection{Statistical Analysis}

An ANOVA was conducted on the absolute errors to determine if the accuracy difference between height estimates among the three remote sensing methods was statistically significant. The results of a p-value of 0.035 concluded

Table 2. Mean error, mean absolute error, mean absolute percent error and RMSE for all 30 remotely sensed building feature height estimates.

\begin{tabular}{ccccc}
\hline & & & 3 & Measurement \\
Error & Actual & & Method \\
\cline { 3 - 5 } Assessment & Height & Pictometry & LiDAR & Laser \\
\hline Mean Height (m) & 3.75 & 3.68 & 3.82 & 3.66 \\
Mean Error (m) & $\mathrm{n} / \mathrm{a}$ & -0.07 & 0.07 & -0.09 \\
Mean Absolute Error (m) & $\mathrm{n} / \mathrm{a}$ & 0.08 & 0.14 & 0.11 \\
Mean Absolute Percent Error (\%) & $\mathrm{n} / \mathrm{a}$ & 2.28 & 4.00 & 2.83 \\
RMSE (m) & $\mathrm{n} / \mathrm{a}$ & 0.11 & 0.16 & 0.14 \\
\hline
\end{tabular}

the difference was significant at the 95\% confidence interval (Table 3). A Tukey pair-wise test was performed and found the LiDAR technique was significantly less accurate than the Pictometry technique, while the laser ranger 
finder technique was not different from the others (Table 4). In measuring building feature height, the Pictometry estimated height on screen within the Pictometry web-based interface achieved the same level of accuracy as using a laser rangefinder in the field. In addition, the Pictometry height estimation was more accurate statistically than height estimated using LiDAR data.

Table 3. Summary table of an ANOVA analysis of absolute error.

\begin{tabular}{|c|c|c|c|c|}
\hline Groups & Count & Sum & Average & Variance \\
\hline Pictometry & 30 & 2.40 & 0.0801 & 0.0062 \\
\hline LiDAR & 30 & 4.15 & 0.1383 & 0.0082 \\
\hline Laser & 30 & 3.18 & 0.1060 & 0.0076 \\
\hline
\end{tabular}

\begin{tabular}{lcrllll} 
ANOVA & \multicolumn{1}{l}{ MS } & F & P-value & F crit \\
\hline Source of Variation & \multicolumn{1}{c}{ SS } & df & MS & & & \\
Between Groups & 0.0511 & 2 & 0.0255 & 3.4802 & 0.0352 & 3.1013 \\
Within Groups & 0.6384 & 87 & 0.0073 & & & \\
& & & & & & \\
Total & 0.6895 & 89 & & & & \\
\hline
\end{tabular}

\section{Conclusions}

The ease of remotely sensed height estimation demonstrated by a senior spatial science undergraduate student using on-screen Pictometry data in a web-based interface and LiDAR data with ArcMap 10.1 GIS software reinforces the use of these methods to estimate height remotely in lieu of in situ assessments. Errors of remotely sensed height estimates, when compared with actual height measurements, were close to zero and ranged from $-0.07 \mathrm{~m}$ to $0.07 \mathrm{~m}$ indicating little difference between estimated and actual height measurements. A Tukey pair-wise test found the remotely sensed Pictometry web-based interface was statistically more accurate than LiDAR data, while the laser range finder was not different from the others. The results indicate that height estimates within the Pictometry web-based interface could be used in lieu of time consuming and costly in situ height measurements.

Table 4. Results from a Tukey pair-wise test.

\begin{tabular}{ccc}
\hline $\begin{array}{c}\text { Measurement } \\
\text { Method }\end{array}$ & $\begin{array}{c}\text { Tukey } \\
\text { Level }\end{array}$ & $\begin{array}{c}\text { Least Square Mean } \\
\text { (meters) }\end{array}$ \\
\hline LiDAR & A & 0.14 \\
Laser & A $\quad$ B & 0.11 \\
Pictometry & & B \\
\hline
\end{tabular}

The findings validate the interactive hands-on instruction methodology employed by the GIS faculty within ATCOFA. Using spatial science technology a senior undergraduate student under the direction of GIS faculty learned how to estimate the height of surface features from a distance using remotely sensed data. The high level accuracy of the students applied height estimates validates the hands-on instruction methodology employed within the Bachelor of Science in Spatial Science program within ATCOFA at SFA. The results validate ATCOFA's mission statement of producing spatial science graduates capable of utilizing spatial science technology to accurately quantify, qualify, map, and monitor natural resources.

\section{Acknowledgements}

This research was supported by McIntire Stennis Cooperative Research funds administered by the Arthur Temple College of Forestry and Agriculture.

\section{References}

Anderson, H., Reutebuch, S., \& McGaughey, R. (2006). A rigorous assessment of tree height measurements obtained using airborne lidar and conventional field methods. Canadian Journal of Remote Sensing, 32(5), 355-366. http://dx.doi.org/10.5589/m06-030 
Asner, G. P., Palace, M., Keller, M., Pereira, R., Silva, J., \& Zweede, J. (2002). Estimating canopy structure in an amazon forest from laser range finder and IKONOS satellite observations. Biotropica. 34, 483-492. http://dx.doi.org/10.1111/j.1744-7429.2002.tb00568.x

Bullard, S., Coble, D., Coble, T., Darville, R., \& Stephens-Williams, P. (2014). Producing 'Society-ready'foresters: A research-based process to revise the Bachelor of Science in Forestry curriculum at Stephen F. Austin State University (ATCOFA Monograph 1-2014). Nacogdoches, Texas: Arthur Temple College of Forestry and Agriculture, Stephen F. Austin State University, Nacogdoches, Texas.

Campbell, J. B., \& Wynne, R. H. (2011). Introduction to Remote Sensing. New York, New York: The Guilford Press.

Chapman, J., Hung, I., \& Tippen, J. (2010). Evaluating TIFFS (Toolbox for Lidar Data Filtering and Forest Studies) in deriving forest measurements from Lidar data. Mathematical and Computational Forestry and Natural Resources Sciences, 2(2), 145-152.

Dailey, S. W. (2008). An accuracy assessment of 3-dimensional measurements derived from LiDAR and Pictometry data when compared to in situ survey measures. Columbia, South Carolina: M. S. Thesis, University of South Carolina.

Electronic Field Study (EFS). (2007). Electronic Field Study User Guide Version 2.7. Rochester, New York: Pictometry International Corporation.

Gatziolis, D., Fried, J., \& Monleon, V. (2010). Challenges to estimating tree height via lidar in closed-canopy forests: a parable from western Oregon. Forest Science, 56, 139-155.

Gerke, M., \& Kerle, N. (2011). Automatic structural seismic damage assessment with airborne oblique pictometry imagery. Photogrammetric Engineering and Remote Sensing, 77, 885-898. http://dx.doi.org/10.14358/PERS.77.9.885

Jurisch, A., \& Mountain, D. 2008. Evaluating the viability of Pictometry imagery for creating models of the build environment. In Proceedings of the Computational Science and its Applications-ICCSA, Perugia, Italy, pp. 663-677.

Maltamo, M., Hyyppa, J., \& Malinen, J. (2006). A comparative study of the use of laser scanner data and field measurements in the prediction of crown height in boreal forests. Scandinavian Journal of Forest Research, 21, 231-238. http://dx.doi.org/10.1080/02827580600700353

O'Beirne, D. (2012). Measuring the urban forest: comparing LiDAR derived tree heights to field measurements. San Francisco, California: M. A. thesis, San Francisco State University.

Popescu, S. C., \& Wynne, R. H. (2004). Seeing the trees in the forest: using lidar and multispectral data fusion with local filtering and variable window size for estimating tree height. Photogrammetric Engineering and Remote Sensing, 70, 589-604. http://dx.doi.org/10.14358/PERS.70.5.589

Popescu, S. C., Wayne, R. H., \& Nelson, R. H. (2002). Estimating plot-level tree heights with lidar: local filtering with a canopy-height based variable window size. Computers and Electronics in Agriculture, 37, 71-95. http://dx.doi.org/10.1016/S0168-1699(02)00121-7

Unger, D. R., Hung, I., \& Kulhavy, D. L. (2014). Comparing remotely sensed Pictometry web-based height estimates with in situ clinometer and laser range finder estimates. Journal of Applied Remote Sensing, 8, http://dx.doi.org/10.1117/1.JRS.8.083590

Unger, D., Kulhavy, D., Williams, J., Creech, D., \& Hung, I. (2014). Urban tree height assessment using Pictometry hyperspatial 4-inch multispectral imagery. Journal of Forestry, 112, http://dx.doi.org/10.5849/jof.14-020

Unger, D., Kulhavy, D., Hung, I., \& Zhang, Y. (2014). Quantifying natural resources using field-based instruction and hands-on applications. Journal of Studies in Education, 4, 1-14. http://dx.doi.org/10.5296/jse.v4i2.5309

Wang, Y., Schultz, S., \& Giuffrida, F. (2008). Pictometry's proprietary airborne digital imaging system and its application in 3d city modelling. International Archives of Photogrammetry and Remote Sensing, 37, 1065-1069. 